\title{
La legislación agraria del New Deal: la Agricultural Adjustment Act
}

\author{
Antonia Sagredo Santos
}

\section{RESUMEN}

El objetivo de esta investigación es realizar un estudio de la principal ley agraria del New Deal, la Agricultural

Adjustment Act, que promueve el

Presidente Franklin D. Roosevelt y aprueba el Congreso estadounidense el 12 de mayo de 1933. Igualmente, se analiza el nuevo organismo, el Agricultural Adjustment Administration $A A A$, creado por el Presidente Roosevelt para establecer las medidas necesarias para desarrollar esta nueva

legislación agraria. La Agricultural

Adjustment Act tiene una gran relevancia ya que con su aplicación se pretende conseguir la recuperación de la agricultura norteamericana, evitando

la extensión del endeudamiento entre los agricultores y propiciando la reducción de los excedentes de productos agrarios básicos.

PALABRAS CLAVE Legislación agraria, Agricultural Adjustment Act, Agricultural Adjustment Administration, New Deal Franklin D. Roosevelt.

\section{ABSTRACT}

The aim of this research is to carry out a study of the main agrarian law of the New Deal, the Agricultural Adjustment Act. It was promoted by President Franklin D. Roosevelt and passed by the American Congress on 12th May 1933. At the same time, the new agency, the Agricultural Adjustment Administration $A A A$, created by President Roosevelt to establish the measures to develop this new piece of agrarian legislation, is analyzed. The Agricultural Adjustment Act has an outstanding relevance because it attempts to recover American agriculture, avoiding the extent of debt among farmers and favouring the reduction of the surplus of basic commodities.

\section{KEY WORDS}

Agricultural legislation, Agricultural Adjustment Act, Agricultural Adjustment Administration, New Deal, Franklin D. Roosevelt. 


\title{
1. ANTECEDENTES
}

Cuando llega el candidato demócrata, Franklin D. Roosevelt, a la Casa Blanca, el 4 de marzo de 1933, en la agricultura norteamericana se está registrando una profunda crisis. El nuevo Presidente fija como objetivo prioritario de su política agraria, elevar el nivel de vida de la población del agro americano, ya que es consciente de las repercusiones favorables que tendría este hecho en la recuperación económica de todo el país, una relación que señala la prensa española coetánea ${ }^{1}$. El propio Presidente manifiesta esta necesidad con sus palabras:

\begin{abstract}
«Cincuenta millones de hombres, mujeres y niños dentro de nuestras fronteras están directamente relacionados con el presente y el futuro de la agricultura. Otros cincuenta o sesenta millones de personas, que tienen negocios o industrias en nuestras grandes ciudades o pequeñas comunidades van a entender finalmente el simple hecho de que su futuro también depende directamente de la prosperidad de la agricultura. Cada vez son más conscientes de que no habrá salida para sus productos a menos que los cincuenta millones de ciudadanos que viven directamente de la agricultura tengan suficiente poder adquisitivo para comprar los productos de las ciudades»?
\end{abstract}

Esta situación crítica que vive el campo norteamericano en los años 30 viene determinada, principalmente, por una serie de hechos que afectan en el primer tercio del siglo $x x$ a la agricultura de los Estados Unidos. A lo largo de estos años, se registran tres períodos claramente diferenciados. El primero se extiende desde 1900 a 1914, durante el cual el agro americano pasa por una etapa muy floreciente, conocida como The Golden Age (época dorada). El segundo se desarrolla durante los años de la Primera Guerra Mundial, 1914-1919, en el que se incrementa la producción agraria, ya que todos los excedentes son absorbidos por el mercado exterior, el europeo preferentemente. Paralelamente al aumento de la producción se produce una subida de los precios agrarios. En el período bélico, se puede afirmar con palabras de Theodore W. Schultz que «la guerra produce un incremento en la demanda de productos agrarios que se caracteriza por un ligero cambio en la producción agraria, un fuerte cambio

\footnotetext{
1 «El campo en el New Deal.- Sin agricultura no prospera la industria», La Libertad, Madrid, V 30-11-1934, última página.

2 Franklin D. Roosevelt, Looking Forward. (1933). New York: Da Capo Press, 1973, págs. 127 y 128. Este mismo párrafo se transcribe en el diario La Libertad de Madrid. «La agricultura en el New Deal.- Las bases de su reconstrucción», J 6-12-1934, pág. 12.
} 
en los precios de los productos del campo y, finalmente, un cambio pronunciado en los ingresos del campo ${ }^{3}$.

En los años de la contienda mundial no se desarrolla ningún plan para ajustar la agricultura americana al período de posguerra, y después del armisticio, los agricultores siguen produciendo "como si el mercado fuera insaciable" " ${ }^{4}$. Como consecuencia, en 1920 se inicia un tercer período, en el que se registra una fuerte depresión debido a su exceso de producción ${ }^{5}$, al gran incremento del endeudamiento del campo ${ }^{6} \mathrm{y}$, finalmente, a que los precios agrarios, sobrevalorados en los años de la guerra, bajan bruscamente. Al mismo tiempo, se produce una relación de desequilibrio entre el precio elevado de los productos que compra el agricultor y la escasa cantidad de dinero que recibe por las mercancías que él vende.

Así pues, en la década de los 20 aparece en la agricultura americana una demanda de intervención directa del gobierno. Las organizaciones del campo crecen rápidamente y comienzan a ejercer una fuerte influencia en la Cámara de Representantes y en el Senado, especialmente a través del Farm Bloc (bloque agrario) ${ }^{7}$. Los que abanderan este grupo son: Chester Davis, George N. Peek, Henry C. Wallace, Hugh S. Johnson y su principal ideólogo Lester J. Dickinson. Basándose en las ideas de Peek y Johnson, el congresista Dickinson, con la ayuda de Davis, trata de articular una ley agraria, en la que se recogen dos ideas básicas: la necesidad de elevar los precios agrarios al nivel de 1909-1914, dando un subsidio al campo y, simultáneamente, implantar un impuesto, an equalization fee (cuota de compensación), por el valor de la diferencia entre el precio de los productos agrarios que se exportan y los que se consumen en el mercado nacional.

3 Theodore W. Schultz, Agriculture in an Unstable Economy. New York: McGraw-Hill Book Co., Inc., 1945, pág. 14.

4 Theodore Saloutos. The American Farmer and the New Deal. Arres, lowa: lowa State University Press, 1982, pág. 15.

5 En los años 20 se usa la expresión The Farm Problem, para referirse al exceso de producción de la agricultura americana. Sobre este tema, véase por ejemplo, Dwight Sanderson, Research Memorandum on Rural Life in the Depression. New York: Social Science Research Council, 1937, pág. 3. Grant McConnelL, The Decline of Agrarian Democracy. Berkeley \& Los Angeles: University of California Press, 1953, pág. 14. William H. Peterson, The Great Farm Problem. Chicago: Herny Regnery Co., 1959, pág. 80.

6 Henry C. WAllace, Our Debt \& Duty to the Farmer. New York: The Century Co., 1925, pág. 30: «Entre 1910 y 1920 el total de las hipotecas de la agricultura norteamericana aumenta de 3.320.470.000 dólares a 7.857.700.000».

7 El Farm Bloc surge en la primavera de 1921 y lo componen veintidós senadores, tanto republicanos como demócratas. El senador Kenyon de lowa es su presidente. Este grupo del Senado impulsa la creación de varias leyes. Su nombre aparece por primera vez en un artículo escrito por el corresponsal en Washington del New York Times, New York, D 28-8-1921. 
En 1922 va a producirse un hecho significativo por sus posteriores implicaciones. George N. Peek, presidente del Moline Plow Co., en Illinois, y su ayudante Hugh S. Johnson publican un folleto con el título Equality for Agriculture (igualdad para la agricultura). En él presentan un plan para corregir la diferencia que existe entre los precios de los productos industriales y los agrícolas, a favor de los primeros. Para conseguirlo, propugnan que se establezca un impuesto sobre los productos del campo, que pagarian los intermediarios y con el que se financiarían las exportaciones agrarias. Igualmente, proponen que la relación existente entre los precios de la industria y de la agricultura debe ser la que existía durante los diez años que precieron a la Primera Guerra Mundial. Las ideas de Peek y Johnson se materializan en un proyecto de ley que aprueba el Senado, y que es patrocinada por el senador McNary de Oregon y el representante Haugen de lowa, conocida como la McNary-Haugen Bill o el McNary-Haugen Plan (proyecto de ley o plan McNary-Haugen) ${ }^{8}$.

La esencia del Plan McNary-Haugen es el doble sistema de precios. Dentro del país se establece un precio alto y en las exportaciones un precio bajo. Se introduce un arancel para proteger la producción nacional y tratar de evitar las importaciones de productos agrícolas. En las primeras versiones del plan, el precio agrario a nivel nacional se mantiene en una relación de igualdad con los precios de los productos no agrarios. En las últimas, se aboga por establecer un precio dentro del país que sea igual al mundial más un arancel.

En el desarrollo del Plan McNary-Haugen se pueden distinguir tres etapas. En 1924, el primer proyecto de ley no pasa el Congreso. En 1927, el segundo supera el Congreso y el Senado, pero es vetado por el presidente Calvin Coolidge. Y finalmente, en 1928, el tercero pasa el Congreso y el Senado y de nuevo el presidente Coolidge lo veta. El Senado lo aprueba, obviando el veto del presidente, pero no supera el Congreso por escasos votos. El historiador Theodore Saloutos considera que este plan "fomenta un nacionalismo económico y un fundamentalismo agrario" y que además no remediaría los males de la agricultura. Por su parte, Murray R. Benedict, también opina que «incluso si se hubiera adoptado, no hubiera solucionado el problema» ${ }^{9}$.

Unos años más tarde, en las elecciones presidenciales de 1928, ningún candidato se compromete a sacar adelante el Plan McNary-Haugen, aun-

\footnotetext{
8 Para un estudio más completo de todo el proyecto se debe consultar el libro de Gilbert $\mathrm{C}$. FIrE, George N. Peek and the Fight for Farm Parity. Norman: University of Oklahoma Press, 1954.

9 Murray R. BENEDICT, Can We Solve the Farm Problem? An Analysis of Federal Aid to Agriculture. New York: The Twentieth Century Fund, 1955, pág. 8. Theodore Saloutos, op. cit., pág. 20.
} 
que prometen algún tipo de acción a favor del campo. Sin embargo, en ese mismo año se produce un hecho que va a influir en la política agraria americana de los años 30 . Henry A. Wallace abandona el partido republicano, al que pertenece por tradición familiar, ya que su padre, Henry $\mathrm{C}$. Wallace, fue Secretario de Agricultura con Warren G. Harding, e ingresa en el partido demócrata llevando con él a George Peek, Hugh Johnson y Chester Davis. Todos ellos son los artífices del Plan McNary-Haugen, algunas de cuyas ideas van a plasmarse en distintas leyes agrarias del New Deal, cuando Henry A. Wallace es designado Secretario de Agricultura por Franklin D. Roosevelt en 1933.

En un momento en que la agricultura americana está recuperándose lentamente de la crisis agraria de 1920, se produce el pánico bursátil de 1929 que provoca una fulminante caída en el índice de precios de los productos agrarios y agudiza el problema de la superproducción. Si se toma como base 100, del período anterior a la Primera Guerra Mundial, descienden de 146, en 1929, a 55, en marzo de 1933. Al mismo tiempo, los bienes que compra el campesino, calculados con la misma base, bajan solamente de 153 a 100 . El agricultor está atrapado en las «proverbiales tijeras» entre los precios de los productos primarios y secundarios ${ }^{10}$.

Después del fracaso del Plan McNary-Haugen, se siguen buscando otras alternativas para solucionar los problemas del campo. En 1929, John D. Black, profesor de Harvard y decano de los economistas agrarios americanos, presenta una primera versión del Domestic Allotment Plan (plan de reparto nacional). Sus principales objetivos son: reducir la producción y elevar los ingresos del agricultor. Para conseguirlo, se fija una cuota de producción para todos los productores de alimentos básicos y, paralelamente, se conceden subsidios a los agricultores que se acojan al programa, que tiene un carácter voluntario y que se financia, en parte, a través de un impuesto que se aplica a la primera transformación de esos productos básicos, conocido como processing tax (impuesto de transformación).

Posteriormente, Milburn L. Wilson, profesor de economía agraria en la Universidad de Montana, desarrolla legislación agraria ayudado por los economistas John D. Black, Howard Tolley, William J. Spillman y Mordecai Ezequiel, como se refleja en la prensa española ${ }^{11}$. El resultado es el Vo-

10 Miriam S. FARLEY, Agricultural Adjustment Under the New Deal. New York: American Council Institute of Pacific Relations, 1936, pág. 7.

11 José PIJOÁN, «Lo que pasa y pasará en los Estados Unidos...», El Sol, Madrid, M 15-81933, primera página. En este artículo, escrito después de haberse aprobado la Agricultural Adjustment Act, se critica a los políticos y su modo de trabajar, al mismo tiempo que se valora positivamente el modo pragmático, profesional, anónimo y directo en que trabajan Milburn L. Wilson y 
luntary Domestic Allotment Plan (plan de reparto nacional voluntario). En diciembre de 1931 presentan el plan en el Federal Farm Board (cámara agraria federal) sin que tenga eco alguno, ya que sus ideas difieren sustancialmente de las que está desarrollando el presidente Herbert C. Hoover en su política agraria.

En los primeros meses de 1932 se constituye un grupo de trabajo para desarrollar el Domestic Allotment Plan, en el que se encuentran: Milburn L. Wilson, Henry A. Wallace, Henry I. Harriman, presidente de la Cámara de Comercio y, Beardsley Ruml, miembro de la Fundación Rockefeller de Nueva York. Rexford G. Tugwell comienza a interesarse por este plan cuando se relaciona con algunos miembros de ese grupo. Paralelamente, el Comité de Agricultura del Congreso nombra un Subcomité para trabajar sobre este asunto y, finalmente, elabora un proyecto de ley que se presenta el 4 de junio de 1932 en la Cámara de Representantes ${ }^{12}$.

El 2 de julio de 1932, Franklin D. Roosevelt pronuncia el discurso de aceptación de su nominación como candidato demócrata, en el que hace referencia a las medidas agrarias que adoptará en el futuro. Aunque no se define abiertamente por el Domestic Allotment Plan, si que introduce sus ideas básicas. Mantiene que elevará los precios de los productos agrarios y para ello: «los agricultores de este país deben aceptar planificar su producción para reducir los excedentes y así no será necesario venderlos al extranjero a bajo precio para mantener el mercado interior " ${ }^{13}$.

Después de la nominación de Roosevelt, se forma un grupo de trabajo para trazar las líneas básicas de su futura política agraria del que forman parte: Rexford G. Tugwell, quien conoce el tema agrario a fondo; Mordekai Ezekiel, economista que trabaja en el Departamento de Agricultura desde los años 20; Henry A. Wallace, futuro Secretario de Agricultura y, Milburn L. Wilson, como ideólogo del Domestic Allotment Plan. El grupo aboga por implantar una reducción de la extensión cultivada y así poder eliminar los excedentes y elevar los precios de los productos agrarios.

el grupo que desarrolla la ley agraria: «estos técnicos no tienen que recibir peticiones ni súplicas de nadie; no tienen que pelearse con políticos; no forman parte de ministerios; se han reclutado ellos mismos su personal de oficina, y no pierden tiempo con visitas, comidas ni tés. En Washington casi nadie los conoce. Se entienden directamente con Roosevelt».

12 Para un análisis más pormenorizado de este proyecto, véase William D. RowLEY, Milburn L. Wilson and the Campaign for the Domestic Allotment. Lincoln, Nebraska: University of Nebraska Press, 1970.

13 Franklin D. RooseveLT, «Speech Before the 1932 Democratic National Convention». ACceptance Speech. Chicago, Illinois, July 2, 1932. En: John Gabriel Hunt (ed.). The Essential Franklin Delano Roosevelt. Avenel, New Jersey: Portland House, 1996, pág. 24. 
Durante su campaña electoral, Roosevelt pronuncia un discurso en la ciudad de Topeka, Kansas, el 14 de septiembre de 1932, donde presenta su futura política agraria, siendo un claro llamamiento al voto del campo, con unos buenos resultados políticos. La estructura del discurso está elaborada por Milburn L. Wilson, y en él se recogen las líneas básicas del Domestic Allotment Plan. El candidato, a esa altura de campaña, ya está familiarizado con el plan, aunque no se decanta abiertamente por él para no restar votos de aquellos que no apoyan totalmente esta iniciativa ${ }^{14}$. Simultáneamente, el Comité de Agricultura del Congreso, presidido por Marvin Jones, trabaja sobre el Domestic Allotment Plan, elaborando un proyecto de ley, la Jones Bill, en la que también se incorporan algunas propuestas de Henry Morgenthau Jr. y de George N. Peek. Este documento se aprueba en el Congreso el 12 de enero de 1933. Este primer borrador de la futura ley agraria se contempla en la prensa española liberal de izquierda ${ }^{15}$.

El 4 de marzo, Franklin D. Roosevelt toma posesión de su cargo y pronuncia su discurso inaugural en el que esboza las dos líneas básicas de su política agraria: «... elevar el valor de los productos agrarios y con ello poder comprar los artículos de las ciudades... (y) evitar la tragedia de la creciente pérdida, a través de la hipoteca de nuestras casas y granjas..." ${ }^{16}$.

La nueva administración demócrata aborda sin dilación el tema agrario, ya que su situación es crítica. En el mes de marzo, el nuevo Secretario de Agricultura, Henry A. Waliace, convoca a cincuenta delegados de las mayores organizaciones del campo y a representantes de la prensa agraria, a una reunión cuyo fin principal es elaborar el borrador de la futura ley agraria, y en la que se retoma la Jones Bill como documento básico de trabajo. El 16 de marzo, Roosevelt envía al Congreso su petición de ayuda para el campo, incluyendo una reducción de la superficie cultivada en algunos cultivos básicos y un sistema de créditos para el agricultor. Les ruega que actúen con diligencia ya que hay que poner en práctica la nueva ley agraria antes de la siembra de primavera, como propone reiteradamente Wallace al Presidente ${ }^{17}$.

14 Governor Franklin D. Roosevelt, Agriculture. What is Wrong and What To Do About It? Speech at Topeka, Kansas, September 14, 1932. New York City: The Democratic National Committee, 1932, pág. 12.

15 «En Norteamérica. Un proyecto que favorece a los agricultores», El Sol, Madrid, X 4-11933, pág. 8.

${ }_{16}$ Franklin D. RooseVELT, «First Inaugural Address», March 4, 1933. En: Richard Hofstadter et al. (eds.). Great Issues in American History. A Documentary Record. New York: Vintage Books, 1959, pág. 354.

17 Carta de Henry A. Wallace a Franklin D. Roosevelt, 22 abril 1933. President's Secretary File, Departamental File, Agriculture, Wallace, Folder 53, Archives, Franklin Delano Roosevelt Library, Hyde Park, New York. 
En el mes de abril, se presenta una nueva enmienda de carácter inflacionista, que tiene posibilidades de ser aprobada en el Senado. Ante este hecho, el Presidente decide aceptar la proposición del Senador Elmer Thomas de Oklahoma, conocida como la Enmienda Thomas, e incorporarla al proyecto de ley agraria. Ese mismo mes, surgen brotes de violencia entre los agricultores al tratar de parar la ejecución de sus hipotecas. Como la ley agraria sigue debatiéndose en la Cámara Alta, a finales de marzo, la organización agraria, Farmers' Holiday Association, convoca una huelga de agricultores para el día 13 de mayo, con el fin de presionar al Congreso y al Senado. Sin embargo, esta huelga no llega a producirse por aprobarse la ley agraria el 12 de mayo.

\section{LA «AGRICULTURAL ADJUSTMENT ACT»: TRES LEYES EN UNA}

La Agricultural Adjustment Act (ley de ajuste agrícola), se aprueba el día 12 de mayo de $1933^{18}$. Esta ley agraria marca el comienzo del New Deal para el agro norteamericano, y a diferencia de las medidas impulsadas por los anteriores gobiernos, Roosevelt promueve una intervención directa del Estado en la agricultura. Algunos historiadores consideran excesivas las funciones que asume el gobierno federal ${ }^{19}$.

En la Agricultural Adjustment Act se recogen las principales propuestas de los dos planes agrarios que se debatían en la década de los 20 en los Estados Unidos: el McNary-Haugen Plan y el Domestic Allotment Plan. Del primero, se introduce la idea de vender los excedentes agrarios al extranjero y los acuerdos comerciales. Del segundo, se incorpora el control de la producción; la cooperación voluntaria de los agricultores, estimulada por unos pagos o rentas; el processing tax (impuesto de transformación) y, la colaboración en la nueva administracción de los agricultores. En palabras de la comentarista contemporánea Miriam S. Farley, la Agricultural Adjustment Act "es una ley lógica y consistente, sus fundamentos teóricos se basan en una década de discusión entre los expertos y la opinión pública» 20 .

18 La Agricultural Adjustment Act (Public N. ${ }^{\circ}$ 10, H.R. 3835, 73d Congress, 1 st session). En: The Secretary of State (dir.). The Statutes at Large of the United States. From March 1933 to June 1936. Vol. XLVIII, Parts 1 \& 2. Washington, D. C.: United States Government Printing Office, 1934, págs. 31-54.

19 Uno de los defensores de esta argumentación es David E. HAMILTON, From the New Day to the New Deal. American Farm Policy from Hoover to Roosevelt, 1928-1933. Chapel Hill \& London: University of North Carolina Press, 1991, pág. 237

20 Miriam S. FARLEY, op. cit., pág. 5. 
En la nueva ley agraria se contemplan tres aspectos totalmente diferentes: el ajuste agrícola, el crédito agrario o ley urgente de hipotecas agrarias de 1933, y la inflación o Enmienda Thomas. Estos tres temas marcan las líneas generales de la política agraria de Roosevelt, cuyos objetivos principales son: elevar el precio de los productos del campo, incrementar el poder adquisitivo del agricultor y, eliminar la superproducción y los excedentes. Para conseguirlos se propone: reducir la extensión de tierra cultivada, disminuir la producción agraria y, tratar de ajustar la oferta a la demanda; a semejanza de lo que ocurre en la industria. Para financiar estas reformas se crea un impuesto, el processing tax, sobre el primer proceso de transformación de determinados productos agrarios, con el que se subvenciona a los agricultores que se acojan al programa.

Roosevelt considera a la agricultura como la pieza clave de su programa de recuperación, pero admite que la ley agrícola es un «experimento» ${ }^{21}$. Edward A. O'Neal, presidente de la organización agraria Farm Bureau, dice que esta iniciativa es "la Carta Magna de la agricultura americana» ${ }^{22}$. El historiador James E. Sargent asegura que esta pieza legislativa es la primera, en la escala de prioridades políticas y económicas de Roosevelt, seguida, aunque no al mismo nivel, por la Economy Act, y la National Industry Recovery Act (NIRA) (ley para la recuperación industrial nacional), formando su «triple programa de prioridades» ${ }^{23}$. Otros autores, aun considerándola uno de los pilares sobre los que se apoya el programa de recuperación de Roosevelt junto con la NIRA, no le dan esa primacía ${ }^{24}$. Raymond Moley, asesor del Presidente, hace hincapié en que esta ley deja una gran capacidad de maniobra a la administración para realizar posteriores concreciones ${ }^{25}$, siendo considerada como una ley "ómnibus" ${ }^{26}$. Por su parte,

21 Franklin D. RooseVeLT, «The New Deal and The Press». Liberty 15 (March 26, 1938), pág. 10.

22 Citado en Orville M. KILE, The Farm Bureau Through Three Decades. Baltimore: The Waverly Press, 1948, pág. 211.

${ }_{23}$ James E. SARGENT, Roosevelt and the Hundred Days. Struggle for the Early New Deal. New York: Garland Publishing, Inc., 1981, pág. 266.

24 Entre estos historiadores podemos mencionar a: Richard H. PELLS, Radical Visions and American Dreams. New York: Harper \& Row Publishers, 1973, pág. 83. Nelson L. Dawson, Louis D. Brandeis. Felix Frankfurter and the New Deal. Westport, Connecticut; Archon Books, 1980, pág. 63. Frank FreIDEL, Franklin D. Roosevelt: His Rendez-Vous with Destiny. Boston: Little Brown \& Co., 1990, pág. 126.

${ }_{25}$ Raymond Moley, The First New Deal. New York: Harcourt, Brace \& World, Inc., 1966, pág. 257.

26 Rexford G. TuxweLL, The Democratic Roosevelt. A Bibliography of Franklin D. Roosevelt. New York: Doubleday \& Co., Inc., 1957, págs. 275-277. William E. LeUCHTENBURG, Franklin D. Roosevelt and the New Deal, 1932-1940. New York: Harper \& Row, Publishers, 1963, pág. 49. Robert McElvalne. The Grat Depression: America, 1929-1941. (1984). New York: Times Books, 1993, pág, 148. 
el representante británico en Estados Unidos, Sir Ronald Lindsay, envía al Foreign Office sus impresiones sobre la ley agraria, destacando que su texto es complejo y que el processing tax repercutirá en las transacciones comerciales futuras ${ }^{27}$.

Evidentemente, la Agricultural Adjustment Act también tiene sus detractores. Entre ellos están los conservadores, que no admiten que el gobierno planifique la agricultura. Fred Britten, representante de Illinois, asegura que "la ley es más bolchevique que cualquiera de las leyes que existen en la Unión Soviética». Joseph W. Martin, de Massachusetts, mantiene «que vamos hacia Moscú» 28.

Igualmente, algunos personajes relevantes de la sociedad americana se muestran contrarios a la medida. Herbert C. Hoover, el ex-presidente republicano, considera que es un "proyecto fascista» ${ }^{29}$. Louis D. Brandeis, miembro del Tribunal Supremo, considera que la ley agraria no es democrática porque el programa es impuesto desde arriba ${ }^{30}$. Por su parte, el historiador Theodore Saloutos asegura que de los tres aspectos que recoge la ley, se desarrollan suficientemente las facetas de ayuda y recuperación, mientras que "se aborta» su parte reformista. Esta idea es compartida por un gran número de autores que mantienen que la ley agraria favorece los intereses de los grandes propietarios, sin atender las demandas de las clases más desfavorecidas ${ }^{31}$.

Esta ley agraria está compuesta por tres partes bien diferenciadas, a las que podrían considerarse como tres leyes independientes. La primera es la Agricultural Adjustment (ajuste agrícola), en la que se otorgan poderes al Presidente, y que éste delega en el Secretario de Agricultura, para tomar medidas dirigidas a incrementar el poder adquisitivo del agro americano. Sólo esta parte está bajo la jurisdicción del Departamento de Agricultura, y de la Agricultural Adjustment Administration ( $A A A$ ) (dirección de

27 Carta de Sir R. Lindsay a Sir John Simon, Washington, 18 mayo 1933. En: Kenneth BouRNE \& D. Cameron WATT (generai eds.). British Documents on Foreign Affairs: Reports \& Papers from the Foreign Office Confidential Print, Part II,(From the First to the Second World War), Series C, Volume 4, Launching the New Deal, March 1933-September 1934. Editado por David K. Adams. Frederick, Maryland: University Publications of America, Inc., 1986, pág. 36.

${ }_{28}$ Citados en Arthur M. Schlesinger, Jr., The Age of Roosevelt. The Coming of the New Deal (1958). New York: The American Heritage Library, 1988, pág. 40.

29 Citado en William H. Peterson, op. cit., pág. 99.

30 Citado en Nelson L. Dawson, op. cit., pág. 73.

${ }_{11}$ Theodore Saloutos, op. cit, pág. 98. Richard S. KIRKENDALl, «The New Deal and Agriculture». En: The New Deal, editado por John Braeman, Robert H. Bremner \& David Brody. Columbus, Ohio: Ohio State University Press, 1975, 1, pág. 93. Robert S. McElvaine, 1993, págs. 162 y 168. 
ajuste agrícola), creada para desarrollar esta sección de la ley. La segunda está compuesta por los Agricultural Credits (créditos agrícolas), y es más conocida como la Emergency Farm Mortgage Act of 1933 (ley urgente de hipotecas agrarias de 1933). En ella se conceden prerrogativas a la Farm Credit Administración ( $F C A$ ) (dirección de crédito agrícola), para adjudicar créditos que ayuden a financiar las hipotecas existentes en la agricultura. Finalmente, la tercera es la Financing or so-called Thomas Amendment (financiación o también conocida como la Enmienda Thomas), en la que se asignan poderes al Presidente para realizar una expansión monetaria y crediticia. Las dos primeras están relacionadas directamente con la agricultura, mientras que la tercera está vinculada a toda la economía del país.

La Agricultural Adjustment Act está precedida por una introducción donde declara sus objetivos: «Es una ley para liberarse de la crisis económica nacional existente elevando el poder adquisitivo agrario, incrementando los fondos para gastos extraordinarios realizados debido a esta crisis, dando ayudas urgentes para paliar la deuda agraria, disponiendo la liquidación ordenada de los bancos agrarios, y para otros propósitos» 32.

\subsection{Título l: ajuste agrícola}

En este apartado se repasa la situación de crisis que vive la agricultura americana y se preve: "Establecer y mantener un equilibrio entre la producción y el consumo de los productos agrícolas... restableciendo los precios a los agricultores hasta un nivel que asegure a los productos del campo un poder de compra con respecto a los artículos que los agricultores adquieren, equivalente al poder adquisitivo de los productos agrarios en el periodo base... agosto 1909-julio 1914. En el caso del tabaco, el período base es... agosto 1919-julio 1929 ${ }^{33}$. Igualmente, se declara que se efectuarán estas correcciones en la agricultura, de forma gradual y protegiendo los intereses de los consumidores.

\section{Parte 1. Contratos de algodón opcionales}

Uno de los principales problemas que presenta la agricultura americana cuando se aprueba la Agricultural Adjustment Act es el gran volumen

\footnotetext{
32 Agricultural Adjustment Act, op. cit., pág. 31.
}

33 Agricultural Adjustment Act, op. cit., pág. 32. 
de excedentes de algodón existente en esos momentos. Se calcula que superan los 12 millones de balas. En consecuencia, el algodón es el primer producto que se aborda en la ley.

En los artículos 3 y 6, la ley otorga poderes al Secretario de Agricultura para ejercer el control sobre todo el algodón que haya recibido ayudas del gobierno, comprándolo a un precio acordado, pero sin superar el precio de mercado. Al mismo tiempo, éste puede firmar contratos con los cultivadores de algodón en los que se establece que deben reducir la cosecha de 1933 al menos un $30 \%$ con respecto a la del año anterior. A cambio, el agricultor puede comprar algodón al Deapartamento de Agricultura, en una cantidad igual a la reducción de la producción pactada y al precio medio estipulado hasta el 1 de enero de 1934. En 1934 pueden firmarse contratos similares.

Igualmente, en los artículos 4, 5 y 7 se establece que el Departamento de Agricultura concederá préstamos a cambio del algodón que almacena o sobre el que controla, utilizando para ello los warehouse receipts (recibos de depósito). Asimismo, se autoriza a la Reconstruction Finance Corporation $(R F C)$ (corporación financiera para la reconstrucción) a facilitar fondos para estos préstamos. Por último, se dispone que el Secretario de Agricultura podrá vender el algodón almacenado según su propio criterio, pero siempre antes del 1 de marzo de 1936.

\section{Parte 2. Productos subvencionados}

En el artículo 11, se enumeran los productos agrarios considerados como básicos y sobre los cuales se establece un control en su producción. Estos son: algodón, trigo, maíz, ganado porcino, tabaco, arroz, leche y sus derivados ${ }^{34}$.

El artículo 8 estipula los poderes que se le conceden al Secretario de Agricultura para reducir la extensión cultivada y así disminuir la oferta de productos agrarios en el mercado que permita subir su precio hasta el nivel deseado. El plan tiene un carácter voluntario, el agricultor puede acceder a controlar su producción y a los beneficios que ofrece el gobierno por reducir sus cosechas si lo desea. También puede establecer marketing

34 La ley Jones-Connally, del 7 de abril de 1934, amplía la lista de productos agrarios controlados por el gobierno con: ganado, cacahuetes, centeno, lino, cebada y sorgo. La Ley del azúcar, ley Jones-Costigan, de 9 de mayo de 1934 incorpora la remolacha azucarera y la caña de azúcar, y finalmente, una enmienda a la ley del 24 de agosto de 1935, añade la patata. 
agreements (acuerdos comerciales), con los que realizan las tareas de transformación, con las asociaciones de productores y todos aquellos que estén relacionados con la manipulación de los productos agrarios. Estos acuerdos comerciales van a ser uno de los principales objetivos de la $A A A$ en $1933^{35}$.

Asimismo, el Secretario de Agricultura puede conceder licencias que permitan a los encargados del proceso de transformación o asociaciones de productores participar en la manipulación o comercialización, nacional o internacional, de cualquier producto agrícola. La concesión de la licencia lleva implícito que puede suspenderse o revocarse si se incumplen los términos o condiciones de la misma, e incluso establece multas para los transgresores. Ésta es una forma de controlar una extensa área de la producción y del mercado.

También, se autoriza al Secretario de Agricultura, en el artículo 10, a establecer Regulations (reglamentos), con fuerza y efecto de ley, sobre los distintos productos agrícolas determinados en el artículo 11. Estos reglamentos van a tener una gran importancia porque en ellos se concretan las medidas que se adoptan para cada uno de los citados productos.

En el artículo 9 y 15 se contempla un aspecto fundamental de esta parte de la ley: la financiación de la política agraria. Para poder limitar y controlar la producción y el mercado agrícola, se dota a la agricultura de un sistema de autofinanciación, y se crea un processing tax (impuesto de transformación). Se establece en el primer proceso de transformación que se realiza en determinados productos agrícolas, y que se estipula para cada uno de ellos, siendo abonado por el que lo realiza. Para subvencionar un producto agrario, se establece el impuesto de transformación sobre ese producto desde el inicio del año comercial. El Secretario de Agricultura fija el valor de ese impuesto, y lo puede ajustar posteriormente para aproximar el precio medio de ese producto y el precio justo del mismo. Se considera precio justo al precio que otorgue un poder adquisitivo al agricultor semejante al que existió en el período base, 1909-1914. Hay algunos casos en que se exime del pago de este impuesto.

El processing tax es uno de los aspectos más polémicos de toda la ley. En Norteamérica se producen numerosas manifestaciones contra la aplicación del nuevo impuesto y sus efectos sobre los productos agrarios.

35 United States Department of Agriculture. Statement of General Policies and Model Drafts For Marketing Agreements and Codes of Fair Competition. Washington, D. C.: United States Government Printing Office, 1933. 
Están en contra de él los que realizan el proceso de transformación, porque ellos son los que tienen que abonarlo; los distribuidores, porque ven incrementado el precio del producto y, los consumidores de las ciudades porque consideran que aumenta el coste de la vida. Aunque se quiere evitar que este impuesto repercuta en los consumidores, los encargados de este proceso elevan los precios de sus productos y, finalmente, el artículo se ve encarecido. Roosevelt ataca con vehemencia la subida de los precios injustificada por parte de los comerciantes:

«Permítanme citarles un ejemplo de un vendedor en una tienda de una gran ciudad del este quien trataba de justificar la subida de precio de una camisa de algodón de un dólar y medio a dos dólares y medio diciendo al cliente que se debía al impuesto de transformación del algodón. En realidad, en esa camisa había una libra de algodón y el impuesto pagado ascendía a cuatro céntimos y cuarto" ${ }^{36}$.

El historiador liberal, Frank Freidel, mantiene que "en teoría pero sólo en teoría, el processing tax que se paga al desmotar el algodón o moler el trigo, no va a repercutir sobre el consumidor" ${ }^{37}$. Sin embargo, una corriente crítica coetánea a la ley pronostica que repercutirá negativamente en otros sectores de la economía. Así, por ejemplo, S. Wells Utley, Presidente de la Detroit Steel Casting Company, asegura que este impuesto:

«Será pagado por los obreros de la industria, tanto los que trabajan como los que están parados, volviendo como un subsidio al agricultor para sobornarle y hacerle reducir su producción de alimentos básicos, así, crean artificialmente una escasez..." ${ }^{38}$.

Paralelamente, a los ingresos que se generan por la aplicación del processing tax, en el artículo 12 se establece una asignación de 100.000.000 de dólares para financiar los pagos que se harán a los agricultores que reduzcan la extensión de sus cultivos, a los que hay que añadir los ingresos que generen los impuestos resultantes de la ampliación de mercados ${ }^{39}$.

${ }^{36}$ Franklin D. Roosevelt, «Fireside Chat», October 22, 1933. En: Russell D. Buhite \& David W. Levy (eds.). F. D. R. 's Fireside Chats. New York: Penguin Books, 1993, págs. 41 y 42

37 Frank Freidel, op. cit, pág. 130.

38 S. Wells Utley, The New Deal. An Address to the $37^{\text {th }}$ Annual Meeting, November 15 , 1933. Chicago: National Founders Asociation, 1933, pág. 8.

39 En este documento se recogen todos los pagos realizados a los agricultores por valor de 10.000 dólares o superiores. United States Department of Agriculture. Payments Made Under The Agricultural Adjustment Program. Letter From The Secretary of Agriculture. Transmitting in Response to Senate Resolution $n .^{\circ} 265$ Certain Information Relative to Payments of $\$ 10,000$ or More 
2.2. Título II: créditos agrarios o ley urgente de hipotecas agrarias de $1933^{40}$

Uno de los mayores problemas que sufre el agro americano cuando se aprueba la Agricultural Adjustment Act es su gran endeudamiento, pues los agricultores están ahogados por sus hipotecas. En 1932, el índice de ejecución de hipotecas alcanza el 30 por mil, mientras que antes de la Primera Guerra Mundial es de un 3 a un 4 por mil ${ }^{41}$. Los agricultores ante lo urgente de su situación se organizan para detener el desahucio y la ejecución de sus hipotecas, llegando a amenazar e incluso agredir a los jueces y agentes de los bancos, como ocurre en la ciudad de Le Mars, lowa, el 27 de abril, donde una muchedumbre enardecida ataca al juez Charles C. Bradley, y esa misma semana en Denison, lowa, un grupo de agricultores agrede a un agente de banco ${ }^{42}$. Ante este estado de cosas, es necesario incorporar a la ley agraria una serie de medidas para financiar las hipotecas agrarias.

Cuando Roosevelt toma posesión de su cargo, los créditos agrarios dependen de varios organismos, públicos y semipúblicos. El nuevo Presidente, en su primer mes de mandato, crea la Farm Credit Administration (FCA) (dirección de crédito agrícola), responsable de gestionar todos los créditos del campo y que complementa, en el mes de junio, con la aprobación de la Farm Credit Act of 1933 (ley de crédito agrícola de 1933). Los organismos creados por estas dos iniciativas del ejecutivo son los encargados de distribuir los créditos entre los solicitantes. Roosevelt asegura que ahora «el crédito federal se ha construido sobre una base de granito en un período de confusión, siendo la base de todo el plan de recuperación» ${ }^{43}$.

En este título II de la ley agraria se contemplan, entre otras, las siguientes medidas:

Los Federal Land Banks (bancos federales agrarios), pueden emitir bonos, por un valor de 2.000.000.000 de dólares, destinados a conceder nuevos préstamos a los agricultores para cancelar sus hipotecas. El interés no superará el $4 \%$ anual y estará garantizado por el Estado.

\footnotetext{
Under The Agricultural Adjustment Program. Washington, D. C.: United States Government Printing Office, 1936.

40 Agricultural Adjustment Act, op. cit., artículos 21 al 42.

41 Murray R. BENEDICT, op. cit., 1955, pág. 49.

42 Arthur M. SCHLESINGER, Jr., op. cit., págs. 42 y 43.

43 Franklin D. RooseVELT, «Third Fireside Chat», July 24, 1933. En: Russell D. Buhite \& David W. Levy (eds.), op. cit., pág. 30.
} 
En los créditos hipotecarios concedidos por asociaciones nacionales de préstamos agrarios o bancos agrarios, se reduce el interés al $4{ }^{\prime} 5 \%$, a pagar en cinco años, y se suspenden los pagos del principal durante ese mismo período si el prestatario cumple lo pactado en su hipoteca.

Se limitan las operaciones de los Joint-Stock Land Banks (bancos agrarios de capital social). La RFC presta dinero a estos bancos, sin que supere el $60 \%$ del valor de sus bienes raíces, reduciendo el tipo de interés al $5 \%$ con el fin de que durante los dos próximos años pospongan la ejecución de las hipotecas de los prestatarios si éstos dejan de pagar.

La RFC destina una suma de 200.000 .000 dólares al Comisario de Crédito Agrario para que conceda préstamos directos a los agricultores con el objeto de: financiar deudas, proporcionar capital para operaciones agrícolas, cancelar hipotecas o comprar tierras sobre las que se haya ejecutado una hipoteca después del 1 de julio de 1931.

Se conceden créditos a los propietarios de tierras con árboles, asignando un valor a éstos, además del que se haya concedido previamente a la tierra.

Se incrementa la cantidad máxima de los créditos individuales de 25.000 dólares a 50.000 .

Asimismo, en los artículos 39 y 40 se especifican los poderes del Comisario de Crédito Agrícola y del gobernador de la FCA. Finalmente, en el artículo 42, se da nombre a todo el título, denominándolo Emergency Farm Mortgage Act of 1933 (ley urgente de hipotecas agrícolas de 1933).

\subsection{Título III: financiación y ejercicio del poder concedido por la sección 8 del artículo I de la constitución: acuñar moneda y regular su valor ${ }^{44}$}

En los Estados Unidos existe en los años 30 una corriente que aboga por introducir medidas de carácter inflacionista, que tiene una amplia difusión en el sur y en el oeste y está representada por un fuerte grupo de presión en el Senado. Así, cuando está debatiéndose el proyecto de ley agraria, el Senador Elmer Thomas de Oklahoma, máximo representante del «Bloque de la Inflación», introduce una enmienda al proyecto de ley agraria. Muchos historiadores coinciden en que el Senado fuerza a Roosevelt a

\footnotetext{
44 Agricultural Adjustment Act, op. cit., artículos 43 al 46.
} 
aceptar esta enmienda, como una más de las medidas agrarias propuestas, a cambio de apoyar la aprobación del conjunto de las mismas ${ }^{45}$.

De este modo, la Enmienda Thomas se incorpora como el Título III de la Agricultural Adjustment Act. Su principal objetivo es promover la expansión monetaria y crediticia, y para ello autoriza al Presidente a tomar estas medidas inflacionistas: aceptar la plata como forma de pago, remonetizar la plata, emitir billetes y bajar el contenido de oro del dólar hasta el $50 \%$. Igualmente, otorga al Presidente unos poderes excepcionales, que éste delega en el Secretario del Tesoro, por los que puede firmar acuerdos con los Bancos de la Reserva Federal y con el Federal Reserve Board (comisión de la reserva federal), a la que autoriza a aumentar o disminuir sus reservas, si se produce una expansión del crédito.

La adopción de esta enmienda en el paquete de medidas agrarias ha sido muy debatida. El asesor de Roosevelt, Bernard M. Baruch, opina despectivamente que es una «ley del populacho, más drástica que la Revolución Francesa" y Lewis Douglas, Director de la Oficina del Presupuesto, va todavía más lejos al afirmar que «éste es el fin de la civilización occidental» ${ }^{46}$. En la prensa española se presentan algunas opiniones sobre esta enmienda ${ }^{47}$.

\section{LA APLICACIÓN DE LA LEY AGRARIA: LA «AGRICULTURAL ADJUSTMENT ADMINISTRATION» (AAA) ${ }^{48}$}

El Presidente crea la Agricultural Adjustment Administration (AAA) (dirección de ajuste agrícola), para ejercer los poderes y conseguir los objetivos propuestos en la Agricultural Adjustment Act. Nombra al Secretario de Agricultura como su máximo responsable y éste, a su vez, delega en

45 Véase a título ejemplo, Arthur M. Schllesinger, Jr., op. cit., pág. 41. Robert S. McElvaine, op. cit., pág. 148 .

46 Citados en Robert S. McElvaine, op. cit, pág. 149.

47 El diario conservador, El Debate, manifiesta que «no se sabe por qué razones se incluye en la ley...». En: "Hace un año que fue promulgada la NRA, la ley clave de la política de Roosevelt.- La agricultura», El Debate, Madrid, D 17-6-1934, primera página, Suplemento Extraordinario. Sin embargo, el rotativo de izquierda, El Liberal de Madrid pronostica que: «El proyecto de plenos poderes para las cuestiones monetarias cuenta con la aprobación de los demócratas, del centro industrial del este y de los representantes agrícolas del medio oeste, y tendrá en contra a los repu blicanos». En: «La economía en los Estados Unidos.- El Senado niega los poderes excepcionales a Roosevelt para la desvalorización del dólar», El Liberal, Madrid, S 22-4-1933, pág. 7.

48 En numerosas ocasiones se identifica, tanto a la Agricultural Adjustment Act como a la Agricultural Adjustment Administration, con las siglas AAA. En este artículo solamente se utilizarán cuando se refieran a la Agricultural Adjustment Administration. 
un administrador que se encarga de dirigir directamente las actividades de dicho organismo. La $A A A$ está integrada en el Departamento de Agricultura y utiliza los medios y recursos del mismo para alcanzar sus propios fines ${ }^{49}$.

El objetivo primordial de la $A A A$ es establecer relaciones fluidas y cordiales con los millones de agricultores repartidos por todo el país, para poder ganar su confianza y propiciar su colaboración voluntaria con el plan, reduciendo su producción agraria para que se produzca una subida de los precios de los productos del campo. Su labor es fundamental en la recuperación del país, y así lo admite Roosevelt cuando manifiesta que «al lado del pilar de la agricultura, la $A A A$, está el de la industria, la $N R A \gg{ }^{50}$.

El administrador es el responsable de dirigir todas las actividades de la AAA y cuenta con el apoyo de tres ayudantes (assistant administrators) y otros tres funcionarios de igual rango: un asesor jurídico, un director financiero y un interventor. Estos están encargados de las seis divisiones más importantes de este organismo: programación y planificación; información y publicidad; control y comercialización de los productos; aspectos legales; presupuesto financiero, y auditoría y contabilidad. A su vez, todas las divisiones tienen sus secciones, cada una de ellas relacionada con un producto agrario. De éstas hay siete, tantas como productos básicos contemplados en la ley agraria. Cada una de ellas tiene su encargado.

El máximo responsable de la $A A A$ es el Secretario de Agricultura, Henry A. Wallace. Éste tiene una relación directa con el campo desde su nacimiento, ya que pertenece a la familia de los Wallace de lowa. Él mismo se encarga del cultivo y cuidado de sus tierras y realiza experimentos para mejorar las especies de maíz. Es autor de varios libros y se hace cargo de la edición de la revista agraria Wallace's Farmer, fundada por su familia ${ }^{51}$.

La elección de Henry A. Wallace como Secretario de Agricultura levanta una cierta polémica en Norteamérica, y el Presidente recibe cartas de

49 Para conocer en detalle la labor de la AAA véase Edwin G. Nourse et al. Three Years of the Agricultural Adjustment Administration. Washington D. C.: The Brookings Institution, 1937.

50 Franklin D. RoosevelT, «Fireside Chat, October 22, 1933». En: Russell D. Buhite \& David W. Levy (eds.), op. cit., pág. 41.

51 Sobre Henry A. Wallace hay abundante bibliografía entre la que se puede citar: RUSSELL LORD, The Wallaces of lowa. Cambridge: The Riverside Press, 1947. DWIGHT MAcDonALD, Henry Wallace. The Man and the Myth. New York: The Vanguard Press, Inc., 1948. Karl M. Schmidt. Henry A. Wallace. Quixotic Crusade. (1948). New York: Vail Ballou Press, 1960. Richard LowITT \& Judith FABRY, Henry A. Wallace's Irrigation Frontier: On the Trail of the Corn Belt Farmer. Norman: University of Oklahoma Press, 1991. 
apoyo hacia Wallace desde los sectores liberales, al mismo tiempo que los conservadores piden que se le aparte del cargo, ya que se relaciona negativamente su nombramiento con sus vínculos familiares, porque su padre, Henry C. Wallace, fue Secretario de Agricultura con el presidente republicano Warren G. Harding, y él mismo milita en el partido republicano hasta 1928, año en que ingresa en el partido demócrata.

En 1932, Rexford G. Tugwell, asesor del Presidente, presenta al futuro Secretario de Agricultura a Roosevelt y le introduce en su círculo. Henry A. Wallace participa activamente en la campaña electoral de ese año a favor de los demócratas. En 1933, cuando Franklin D. Roosevelt forma su gabinete, elige para desempeñar el puesto clave de su política agraria a un defensor del Domestic Allotment Plan, encargando la cartera de agricultura a Henry A. Wallace, quien desempeña ese cargo durante sus dos primeros mandatos. Al mismo tiempo nombra a otro artífice del plan, Rexford G. Tugwell, como Subsecretario de Agricultura, con el apoyo de Wallace. En la sociedad norteamericana la figura de Tugwell tiene una amplia repercusión, debido al protagonismo que desempeña en la política agraria del New Deal, y sobre todo por sus ideas comunistas, recibiendo un apoyo abierto desde los sectores de izquierda y continuos ataques desde las líneas conservadoras.

Henry A. Wallace está firmemente convencido de que la agricultura desempeña un papel importante en el desarrollo de los pueblos. Como Secretario de Agricultura, él lleva a cabo una labor fundamental, y él es quién se enfrenta a la difícil y penosa tarea de destruir parte de las cosechas, que, debido al retraso en la aprobación de la ley, ya están sembradas. Wallace afronta el reto, como queda reflejado a continuación:

«Cómo están las cosas ahora, nuestros millones de acres de excedentes no crean nada más que confusión, pobreza y dinero malgastado... Hasta que nuestra gente no tenga la visión para poder adoptar una política comercial a largo plazo... nosotros debemos encargarnos del delicado proceso de reducir la producción de los productos básicos» ${ }^{52}$.

Para dar mayor capacidad de maniobra a la $A A A$, el Secretario de Agricultura delega su autoridad sobre la misma en un administrador, que elige el Presidente. Roosevelt, para ganarse el apoyo de los sectores más conservadores, anuncia que va a nombrar administrador de la $A A A$ a George

52 Henry A. Wallace, America Must Choose. New York: Foreign Policy Association, 1934, pág. 4. 
N. Peek, principal impulsor, en la década de los 20, del McNary-Haugen Plan $^{53}$. A pesar de que la base de toda la política agraria es el control de la producción, George N. Peek no lo considera el principal objetivo de su programa, dando prioridad a los acuerdos comerciales y a la venta de excedentes a otros países. El historiador liberal Frank Freidel señala la contradicción en el nombramiento de un notable oponente de la limitación de las cosechas, para dirigir el programa de reducción de la producción. Por su parte, el también liberal, Robert S. McElvaine, considera que si bien es una medida políticamente oportuna a corto plazo, va a convertirse en un gran error encomendarle el desarrollo de un plan que él «básicamente desaprueba» ${ }^{54}$.

Las posturas irreconciliables de Henry A. Wallace y George N. Peek, son manifiestas desde su nombramiento. Peek, al no estar de acuerdo con su superior, decide tratar los asuntos de la $A A A$ directamente con el Presidente, situación que no acepta Wallace y así se lo hace saber a Roosevelt ${ }^{55}$. Wallace piensa que los acuerdos comerciales y el control de la producción están disociados, y que esos acuerdos incrementan poco el poder adquisitivo del campo americano.

En otoño de 1933, el Secretario Wallace critica públicamente los acuerdos comerciales que propone Peek y le veta un plan para vender mantequilla a Europa a bajo precio. En el Departamento de Agricultura es insostenible la situación creada por las dos políticas agrarias existentes: la de Henry A. Wallace y Rexford G. Tugwell y la de George N. Peek ${ }^{56}$. La armonía existente entre Wallace y Tugwell en la defensa de las iniciativas agrarias de Roosevelt se refleja en la prensa norteamericana, en la que el rotativo New York Herald Tribune lo hace a través de caricaturas, introduciendo un tratamiento irónico del tema ${ }^{57}$.

Ante el retraso en la aplicación del programa agrario, en el otoño de 1933 se registran violentas protestas de los agricultores, en las que se

53 Franklin D. Roosevelt recibe numerosos escritos en noviembre de 1932 proponiendo a George N. Peek como Secretario de Agricultura. Entre ellos podemos destacar una carta de Henry A. Wallace, 17 noviembre 1932. President's Secretary File, Departmental File, Agriculture, Wallace, Folder 53, Archives, Franklin D. Roosevelt Library, Hyde Park, New York.

54 Frank Freidel, op. cit, pág. 103. Robert S. McElvalNe, op. cit., pág. 148.

55 Carta de Henry A. Wallace a Franklin D. Roosevelt, 15 mayo 1933. President's Secretary File, Departmental file, Agriculture, Wallace, Folder 53, Archives, Franklin D. Roosevelt Library, Hyde Park, New York.

56 Este tema ha sido abordado reiteradamente en la historiografía sobre el New Deal. Véase por ejemplo, Murray R. BENEDICT, op. cit., pág. 284. Kenneth S. Davis, FDR. The New Deal Years, 1933-1937. (1979). New York: Random House, 1986, pág. 278.

57 Carlisle, "Well, Who Started It, Now?", New York Herald Tribune, New York, S 28-4-1934. 
llega a pedir la dimisión del Secretario de Agricultura. En la prensa española de izquierda se destaca el espíritu de protesta y la lucha desafiante de los agricultores:

"Las cosas van tomando un aspecto algo inquietante en los Estados Unidos, Roosevelt ha creído que sería suficiente elevar el nivel de los precios para equilibrar la situación... los granjeros... para comprarse un traje necesitan vender el doble de algodón o de trigo que hace unos meses. El granjero no se resigna a esta situación, y ha manifestado su decisión de defenderse. No comprará más ni venderá sus productos si no es al precio debido, y si es necesario abandonará su casa y dejará que vendan sus bienes..., si alguien se atreve a ello» ${ }^{58}$.

Para calmar los ánimos de los campesinos, el Presidente anuncia nuevas ayudas, y aparta a George N. Peek de la dirección de la $A A A$ a finales de 1933. Chester $C$. Davis, un granjero de Montana que también es periodista, es el nuevo administrador de la $A A A$, aunque Davis ha sido un estrecho colaborador de George N. Peek en el Plan McNary-Haugen. Sin embargo, Davis llega a la conclusión de que Peek fomenta un excesivo crecimiento del nacionalismo económico con su plan y se convence de que los Estados Unidos deben reducir su tierra cultivada. Con la llegada de Chester $\mathrm{C}$. Davis a la dirección de la $A A A$ y, en los tres años que permanece al frente de la misma, el control de la producción pasa a ser el primer objetivo de este organismo.

Sobre las personas que trabajan en la $A A A$ se producen opiniones encontradas. Frank Freidel mantiene que la $A A A$ no funciona bien durante su primer año, periodo en que se encuentra George N. Peek al frente de la misma ${ }^{59}$, mientras que el escritor coetáneo, Boake Carter, considera que aunque «creada bajo ideales económicamente sólidos, la $A A A$ llega a prostituirse por la falibilidad humana» ${ }^{60}$. Sin embargo, el historiador Arthur M. Schlesinger, Jr., opina que «el éxito de este organismo se debe a su brillante administración" ${ }^{61}$. Igualmente, en un sector de la prensa coetánea norteamericana se hace un balance positivo de la labor de la AAA, como se refleja en el periódico neoyorquino New York Post donde se da un apoyo abierto a este organismo.

\footnotetext{
58 «Los granjeros yanquis contra el gobierno», La Libertad, Madrid, V 3-11-1933, última página.

59 Frank FreIDEL, op. cit., pág. 131.

6o Boake CARTER, Johnny Q. Public Speaks. The Nation Appraises the New Deal. New York: Dodge Publishin Company, 1936, pág. 49.

61 Arthur M. SCHLESINGER, Jr., op. cit., pág. 72.
} 
«En menos de tres años, a través de la AAA, la administración Roosevelt ha invertido una tendencia de constante declive que ha dominado durante casi dos décadas" 62 .

Sin embargo, en la historiografía posterior se registra una tendencia en la que se analiza con objetividad y un cierto distanciamiento de los hechos, comprobándose que «excepto para la producción de algodón y tabaco, los programas de control fueron relativamente ineficaces. Las grandes sequías de 1934 y 1936 hicieron mucho más para reducir la producción en los 30 que los programas de control de la $A A A »{ }^{63}$.

\section{PRINCIPALES ACCIONES DESARROLLADAS POR LA AAA}

Para conseguir los principales objetivos fijados en la Agricultural Adjustment Act, la $A A A$ se encarga de desarrollar algunos métodos contemplados en la ley agraria ${ }^{64}$. Entre ellos, debido a su gran incidencia en la agricultura norteamericana, se pueden destacar por un lado, el control de la producción, y por otro, los acuerdos sobre la comercialización.

\subsection{El control de la producción}

Ante la excesiva oferta de productos del campo hay dos posibles alternativas: incrementar la demanda o disminuir la oferta. El historiador Carl $\mathrm{N}$. Degier mantiene que «al no encontrar el gobierno ninguna forma de ampliar el mercado, opta por reducir la producción como la única alternativa factible» ${ }^{65}$. El gobierno adopta la segunda opción como manifiesta el Secretario de Agricultura, Henry A. Wallace, cuyas palabras transcribe el diario catalán La Vanguardia:

«(Que) la inflación no es un «cúralotodo» y que los intentos de fijar los precios sin controlar la producción son peligrosos y están condenados al fra-

62 Editorial. «Roosevelt Challenges The Demagogues of Discontent", New York Post, New York, M 10-12-1935, pág. 14.

63 Uno de los autores que postula este argumento es Williard W. Cochrane. The Development of American Agriculture. A Historical Analysis. Minneapolis, Minnesota: University of Minnesota Press, 1993, pág. 317.

64 Para un estudio más detallado de los resultados obtenidos en los dos primeros años de la aplicación del plan véase United States Department of Agriculture. Agricultural Adjustment 1937 to 1938. Washington, D. C.: Unites States Government Printing Office, 1936.

65 Carl N. Degler, Out of our Past: The Force That Shaped Modern America. (1959). New York: Harper, 1984, pág. 418. 
caso. Desarraigar el algodón de diez millones de acres, degollar cinco millones de cerdos, habrían dicho que era locura antes de la guerra, cuarido los Estados Unidos era una nación deudora» ${ }^{6}$.

El autor marxista, Louis M. Hacker, quien no apoya las reformas agrarias de Roosevelt por considerar que su principal objetivo es mantener en pie al sistema capitalista, critica la limitación de la producción y asegura que se convierte en una de las bases de toda la política agraria ${ }^{67}$. Sin embargo, Milo Reno, el líder de la organización campesina Farmers' Holiday Association, considera que el problema es el bajo consumo y no el exceso de producción ${ }^{68}$. Por su parte, el historiador Robert S. McElvaine, aunque su ideología es liberal valora negativamente el plan del gobierno de elevar los precios agrícolas a cambio de «subvencionar la escasez»69, coincidiendo con la crítica del diario obrero de tendencia comunista Mundo Obrero:

«En Virginia se queman toneladas de algodón..., aunque millares de trabajadores del campo deban morirse de hambre y vayan a engrosar los ya inmensos ejércitos de parados" 70 .

Los argumentos esgrimidos por el diario Mundo Obrero tienen un sentido claramente retórico y demagógico, limitándose a criticar las acciones emprendidas por la administración demócrata para tratar de reducir el exceso de producción. Sin embargo, no presenta alternativas para incrementar el consumo, dada la inelasticidad de la demanda de productos agrícolas, a la que hay que considerar como un hecho irremediable, y sólo cabe incrementarla sensiblemente a base de abrir nuevos mercados extranjeros.

En el momento de aprobar la Agricultural Adjustment Act los cultivos ya están sembrados y se pronostica para 1933 una abundante cosecha. Ante estas previsiones, la recién creada AAA pone inmediatamente en marcha todos sus recursos. Comienza enviando agentes, preferentemente al sur y suroeste, para persuadir al agricultcr para que firme contratos en los que se compromete a reducir sus cosechas. Así, se establece un control en la

\footnotetext{
66 «Política agraria», La Vanguardia, Barcelona, J 21-9-1933, pág. 23.

67 Louis M. HACKER, «The Third American Revolution». En: The New Deal. Revolution or Evolution?, editado por Edwin C. Rozwenc. Boston: D. C. Heath \& Co., 1959, pág. 3.

68 Citado en Arthur M. SCHLESINGER, Jr., op. cit., pág. 42.

69 Robert S. McElvaine, op. cit, pág. 148.

70 "Crece la agitación social en Norteamérica.- La bancarrota de la agricultura...", Mundo Obrero, Madrid, J 16-8-1934, última página.
} 
producción de estos siete productos agrarios contemplados en la ley: algodón, trigo, maíz, ganado porcino, tabaco, arroz y leche y sus derivados, adoptando estrategias distintas para cada uno de ellos.

\subsubsection{Algodón ${ }^{71}$}

En los años treinta se produce un descenso del consumo del algodón americano en el resto del mundo, pasando de 15 millones de balas en 1928-1929 a sólo 11 millones en 1930-1931. Paralelamente, el precio del algodón cae desde una media de 18 centavos por libra en 1928-1929 hasta 4'6 centavos, en junio de 1932, que es el precio más bajo, y 5'5 centavos la libra, en febrero de 1933.

En 1933 hay 26 millones de balas de algodón, y aproximadamente la mitad son excedentes de años anteriores. Así pues el gobierno decide eliminar 10 millones de acres, el equivalente a 3 millones de balas de la cosecha de 1933. El plan implica que los agricultores acepten voluntariamente la destrucción de parte de sus cosechas, y a cambio reciban como compensación, pagos en efectivo y una opción de venta de su algodón al gobierno ${ }^{72}$.

A pesar de haber limitado la producción de algodón, en 1933 se recoge una abundante cosecha, 13.047 .000 balas, superando las 13.002 .000 de 1932. Ante este resultado inesperado se interviene el precio del algodón y la $R F C$, a través de la recién creada Commodity Credit Corporation (CCC) (corporación de crédito a los productos agrarios), concede préstamos de 10 centavos por libra de algodón sin vender, a los productores que participen en el programa de control de la producción ${ }^{73}$. En 1933, los cultivadores de algodón son reacios a firmar contratos con la $A A A^{74}$. Así, para

\footnotetext{
71 United States Department of Agriculture. Agricultural Adjustment. Washington, D. C.: United States Government Printing Office, 1934, págs. 19-41.

72 Carta de Franklin D. Roosevelt a Henry A. Wallace, 8 julio 1933. Official File, Department of Agriculture, Folder 1K, Archives, Franklin D. Roosevelt Library, Hyde Park, New York. Para una más detallada información sobre este tema, véase Harvey WISH, Contemporary America. The National Scene Since 1900. New York: Harper \& Brothers Publishers, 1945, pág. 447. William E. Leuchtenburg, op. cit., 1963, pág. 73. Sean D. CASHMAN, America in the Twenties and Thirties. The Olympian Age of FDR. New York \& London: New York University Press, 1989, pág. 166.

73 Carta de Oscar Johnston a. Franklin D. Roosevelt, 8 noviembre 1933. Official File, Agricultural Adjustment Administration, Folder 1K, Archives, Franklin D. Roosevelt Library, Hyde Park, New York.

74 Robert F. HUNTER, "The AAA Between Neighbours: Virginia, North Carolina and the New Deal Farm Program». The Journal of Southern History XLIV/4 (nov. 1978), pág. 541.
} 
reforzar el programa, se aprueba la Cotton Control Act (ley del algodón), conocida como Bankhead Act, el 21 de abril de 1934. En consecuencia, la producción de algodón se reduce a 9.636 .000 balas en 1934 y a 10.638.000 en 1935.

Los precios que reciben los productores suben considerablemente. Durante el período comprendido entre los meses de enero y abril de 1933, son de 5'5 a 6'1 centavos por libra. Después de la aplicación del programa de control de producción y la depreciación del dólar se produce una subida hasta 10' 6 centavos en julio, momento en que alcanza el valor máximo. En agosto y septiembre los precios descienden a 8'8, y vuelven a subir a 9'6 en noviembre y diciembre.

La prensa liberal de izquierda española se hace eco de la satisfacción gubernamental con los resultados del plan, al que da un apoyo abierto: «El Gobierno considera que sus esfuerzos para reducir la producción del algodón han obtenido el mayor éxito...»75. Sin embargo, en la prensa obrera se ofrece un juicio interpretativo negativo sobre ese control, reiterando su postura de rechazo ante las medidas del New Deal y poniendo en duda el valor reformista de las mismas:

«Por acuerdo del Gobierno será destruido uno de estos días un cuarto de la actual cosecha. Como indemnización por la pérdida que ello significa para las empresas explotadoras del algodón, el Estado les abonará 100 millones de dólares... Al presente, 700.000 plantadores se han comprometido a inutilizar una parte cie sus productos. He aquí el panorama que ofrece la llamada revolución yanqui: 76 .

\subsubsection{Trigo ${ }^{77}$}

Los productores de trigo se encuentran ante una situación difícil, disminuye la demanda de trigo norteamericano al incrementarse la producción mundial de ese cereal, especialmente en Europa, donde se adopta una política proteccionista, concediendo subvenciones y adoptando aranceles para gravar sus importaciones.

La situación del trigo es muy distinta a la del algodón. En 1933, no hay necesidad. de adoptar medidas de forma urgente, debido a la reducción

\footnotetext{
75 «La política de restricciones en los Estados Unidos», El Sol, Madrid, X 19-7-1933, pág. 6.

76 "Nota internacional.- Nuevo aspecto de la revolución yanqui», El Socialista, Madrid, V 118-1933, primera página.

77 United States Department of Agriculture, op. cit., 1934, págs. 43-67.
} 
natural que provoca la sequía. Sin embargo, a largo plazo es necesario planificar una disminución de la extensión cultivada a nivel internacional. En el verano de 1933, se celebra en Londres la Conferencia Económica Mundial. En ella se alcanzan algunos acuerdos con respecto al trigo: controlar su producción y sus exportaciones, limitando las cantidades que se puede exportar de la cosecha de 1933-1934; estimular su consumo y reducir las barreras arancelarias de los países importadores. En 1933, Norteamérica también tiene establecido un sistema arancelario que grava las importaciones de productos agrícolas del extranjero, protegiendo así su agricultura.

El acuerdo internacional firmado en la Conferencia de Londres tiene una incidencia directa sobre el plan de reducción de la producción de trigo adoptado por la $A A A$. Así pues, los Estados Unidos establecen una disminución de un $15 \%$ de la extensión cultivada en el período base de 1930$1932^{78}$.

El objetivo fundamental del programa de control del trigo es ayudar a los agricultores a reducir su producción de forma permanente, para conseguirlo el Gobierno les concede subvenciones. El plan contempla los años 1933, 1934 y 1935. En 1933 se preve una reducción de la extensión cultivada del $15 \%$ y del $20 \%$ para los dos años siguientes, con respecto al período base establecido. Cada productor recibe 28 centavos por bushel para el año comercial de 1933-1934 ${ }^{79}$. Los fondos para realizar estos pagos se obtienen del impuesto, processing tax, que se paga al moler el trigo para el consumo humano y se establece en 30 centavos por bushel.

Con respecto a la incidencia del processing tax sobre el trigo, a pesar de los esfuerzos realizados por parte Gobierno para que este gravamen sea absorbido íntegramente por el que realiza el proceso de transformación, se constata que se incrementa el precio de la harina al por mayor, y parte de ese tributo revierte en el consumidor al subir el precio del pan ${ }^{80}$.

De 1.200.000 productores de trigo del país, 550.000 firman contratos, representando el $77 \%$ del total de la extensión de trigo de Estados Unidos en el período 1930-1932. Se eliminan de la producción 7.595 .000 acres, lo que representa un 11 ' $5 \%$ de la extensión cultivada anualmente durante el

78 Para un análisis más pormenorizado de este tema, véase Joseph S. DAvIs, Wheat and the AAA. Washington, D. C.: Brookings Institution, 1935.

79 El bushel es una medida de áridos que en los Estados Unidos equivale a $35^{\prime 2} 237$ litros y en el Reino Unido a 36'367.

${ }_{80}$ Carta de Henry A. Wallace a Louis M. Howe, 12 julio 1933. Official File, Department of Agriculture, Folder $1 \mathrm{~K}$, Archives, Franklin D. Roosevelt Library, Hyde Park, New York. 
período base. Paralelamente, se elevan los ingresos de los agricultores procedentes de las cosechas de trigo, incluyendo las subvenciones, de 169 millones de dólares en 1932-1933, a una cantidad aproximada de 376 millones de dólares para la campaña 1933-1934.

La sequía es la principal causa de la reducción de la cosecha de trigo de 1934. Esta catástrofe natural pone de relieve que los críticos y demagogos habían pronosticado hambre, algunos incluso queriendo culpar de ello al gobierno, y eso obliga a Henry A. Wallace a negarlo en una declaración pública comentada en la prensa española: «El Secretario de Agricultura, Henry Wallace, manifestó que, a pesar de las enormes pérdidas que ha sufrido la cosecha de trigo por la sequía y el polvo, los Estados Unidos no están en peligro de pasar hambre» ${ }^{81}$.

\subsubsection{Maíz y ganado porcino ${ }^{82}$}

La situación de la producción de maíz y la cría de ganado porcino están íntimamente relacionadas ya que este cereal se emplea como su alimento básico. Después de la guerra, incrementan su cría los países europeos, especialmente Alemania y Dinamarca. De este modo las exportaciones americanas a Europa disminuyen, a lo que también contribuye el establecimiento de altos aranceles por parte de los países europeos. Así, se producen unos excedentes de ganado porcino que el mercado nacional no puede absorber y se registra una caída de los precios, que se agudiza en la primavera de 1933, debido en parte al nacimiento de nuevos lechones.

Como primera medida para absorber parte de los excedentes, la $A A A$ compra 222.149 cerdas y más de 6.188 .717 cerdos para sacrificarlos, con un coste de 34 millones de dólares, consiguiéndose una reducción de 1.000 a 1.200 millones de libras, sobre el $10 \%$ del total anual de la carne sacrificada.

La producción de maíz, al estar relacionada con la cabaña porcina, igualmente tiene problemas de excedentes que van a ser utilizados para otros usos menos lucrativos, con la consiguiente caída de los precios. La $A A A$ adopta un sistema de préstamos sobre el maíz almacenado. En 1933, ascienden a 45 centavos por bushel. Posteriormente, debido, en

\footnotetext{
81 «En los Estados Unidos.- Se ha desencadenado una formidable tempestad de polvo que causa diariamente dos millones de dólares de pérdidas.- Enormes pérdidas en la cosecha de trigo", Luz, Madrid, V 11-5-1934, pág. 16.

82 United States Department of Agriculture, op. cit., 1934, págs. 97-152.
} 
parte, a los efectos de la sequía, se elevan a 50 centavos en 1934, para competir con los precios de mercado. Asimismo, se propone una reducción en la producción para 1934 y 1935, a través de la firma de unos contratos ${ }^{83}$, informando en este sentido la prensa norteamericana ${ }^{84}$. El coste de este programa se financia con dos tipos de processing tax, uno sobre el ganado porcino y otro sobre el maíz.

La $A A A$ recalca que el programa para el maíz y el ganado porcino debe considerarse como un todo y mantiene que «en general los ingresos de los productores que participan durante el período, noviembre 1933 a mayo de 1934 , son mayores que los de aquellos que no participan en el programa» ${ }^{85}$. La cosecha de 1934 se ve reducida de forma natural por la sequía y sus efectos se dejan sentir especialmente en el incremento de los precios.

\subsubsection{Tabaco ${ }^{86}$}

El tabaco, aunque no es un producto tan perecedero como los cereales, y en principio tiene mejores posibilidades de almacenaje y comercialización, sufre el mismo problema que el resto de los productos agrícolas: su gran volumen de excedentes. Sin embargo, al mismo tiempo, presenta unas características propias: mientras disminuyen los ingresos de sus productores, se incrementan los beneficios de los que manufacturan el producto.

Los ingresos producidos por las ventas de todos los tipos de tabaco descienden de 286 millones de dólares en 1929 a 107 millones en 1932. La $A A A$ diseña un programa para reducir la producción y liquidar los excedentes. Cada tipo de tabaco va a tener una forma de intervención diferente. Se inicia en 1933 solamente para el tabaco de puro, aunque para todos ellos se incluye un control de producción en los años 1934 y 1935. Los cultivadores de tabaco firman contratos en los que se comprometen a reducir entre un $25 \%$ y $50 \%$ la extensión de sus tierras cultivadas. A cambio, los productores reciben dos tipos de compensaciones: una renta por la extensión que dejan baldía y una compensación, basada en un porcentaje del valor de la cosecha. Los pagos son financiados a través de un processing tax, entre 2 y 4 '2 centavos por libra, dependiendo del tipo de tabaco que se trate.

\footnotetext{
83 Carta de Henry A. Wallace a Franklin D. Roosevelt, 24 noviembre 1934. President's Secretary File, Departmental File, Agriculture, Wallace, Folder 53, Archives, Franklin D. Roosevelt Library, Hyde Park, New York.

84 Véase como ejemplo «Farmers to Get $\$ 15$ for Every Hog They Don't Raise», Detroit Sunday Night, Detroit, S 24-11-1934, pág. 2.

${ }_{85}$ United States Department of Agriculture, op. cit., 1934, pág. 250.

86 United States Department of Agriculture, op. cit., 1934, págs. 69-95.
} 
En 1934, se considera que el plan reduce la cantidad de tabaco en un $28 \%$, con respecto a la de 1933 . Los precios de algunas clases de tabaco, así como el total de ingresos de los cultivadores, aumentan considerablemente durante el primer año en que se estable el control de la producción. Para reforzar este programa se aprueba la Kerr-Smith Act, ley del tabaco, el 28 de junio de 1934.

\subsubsection{Arroz $^{87}$}

Norteamérica ha sido un país exportador de arroz desde la guerra de 1914-1919. Entre 1921 y 1929 el precio del arroz se sitúa en torno a 1'10 dólares por bushel, desciende a 78 centavos en 1930; a 48 centavos en 1931 , y a 39 centavos en 1932. En este descenso de los precios influyen las excepcionales cosechas de 1930 y 1931 , con las que los excedentes pasan de 81 millones de libras en 1930 a 220 millones en 1932.

En el caso del arroz, debido a la bajada de precios se había establecido un recorte en la producción desde 1930. Así pues, la $A A A$ hace el reajuste firmando acuerdos comerciales, a través de los cuales los molinos pagaban unos precios mínimos establecidos. En consecuencia, el precio del arroz pronto alcanza el nivel del mercado internacional.

\subsubsection{Leche y sus derivados ${ }^{88}$}

Los precios de la leche y sus derivados bajan de forma notoria desde un índice del $140 \%$ en 1929 a $123 \%$ en $1930,94 \%$ en $1931,71 \%$ en 1932 , y $59 \%$ en marzo y abril de 1933 . La $A A A$ adopta un programa de control de la producción sobre este producto con el rechazo de todo el sector. La intervención se centra en la erradicación de las vacas enfermas y la compra de ganado como medida de ayuda. Al igual que en el caso del arroz se utilizan los acuerdos comerciales y las licencias como principales medios para elevar los precios, sin que tengan demasiado éxito, debido principalmente, a que sólo un pequeño número de productores de leche se adhieren a estas medidas ${ }^{89}$.

87 United States Department of Agriculture, op. cit., 1934, págs. 173-179.

88 United States Department of Agriculture, op. cit., 1934, págs. 153-172.

89 Anthony J. BADGer, The New Deal. The Depression Years, 1933-1940. (1989). New York: Hill \& Wang, 1995, pág. 155. Para conocer en detalle la política de la AAA con respecto al sector 
En la prensa española obrera coetánea se valora negativamente la imposición de licencias en la industria lechera por parte del Estado ${ }^{90}$. En cambio, en los periódicos de izquierda se considera necesaria la intervención del gobierno para evitar el encarecimiento de la leche debido a los efectos de la sequía: «los precios suben en forma desproporcionada, y el Gobierno parece dispuesto a intervenir de manera enérgica, a fin de evitar toda clase de posibles abusos. Esta decisión del Gobierno ha causado una impresión favorable en la opinión, donde se iba generalizando el malestar por el encarecimiento desproporcionado de muchos artículos de primera necesidad» ${ }^{91}$.

\subsection{Los acuerdos comerciales, licencias y códigos $^{92}$}

Además de los programas de control de la producción, la Agricultural Adjustment Act establece otros poderes, por los que autoriza al gobierno a firmar acuerdos comerciales con productores, intermediarios o distribuidores de cualquier producto agrario, considerado básico o no. Su objetivo es elevar los precios que se pagan a los agricultores por sus productos y mejorar los procesos de transformación y comercialización, sin que se incrementen los precios de los productos en destino.

Simultáneamente, la $A A A$ trata de evitar que repercuta esa subida de precios en el consumidor, y para ello crea el Consumers' Counsel (oficina del consumidor), bajo la dirección de Frederic C. Howe, que centra sus actividades en analizar los acuerdos comerciales y los estatutos establecidos, buscando sus posibles repercusiones sobre el consumidor, y realizando estudios sobre los precios en origen y al consumidor de los productos agrarios, que publica en un boletín que se edita quincenalmente bajo el título Consumers' Guide.

A través de los acuerdos comerciales el gobierno actúa como juez y parte entre asociaciones de productores, transformadores y distribuidores de productos agrarios, para llegar a un acuerdo sobre el precio que van a

\footnotetext{
lácteo debe consultarse la obra de John D. Black. The Dairy Industry and the AAA. Washington, D. C.: Brooking Institution, 1935.

90 «... Se impone a la industria lechera la obligación de obtener la licencia del Estado», El Socialista, Madrid, X 2-8-1933, primera página.

91 Enviado especial de El Sol. «Estados Unidos.- Campaña contra el encarecimiento de la leche», El Sol, Madrid, J 23-8-1934, pág. 3.

92 United States Department of Agriculture. The Agricultural Adjustment Act and Its Operation. Washington, D. C.: United States Government Printing Office, 1933, págs. 5, 6 y 11.
} 
pagar al agricultor por sus mercancías. Para reforzar los términos de los acuerdos comerciales, el Secretario de Agricultura está autorizado a conceder licencias condicionales a los encargados del proceso de transformación y a los distribuidores, y también puede anularlas si no se cumplen las condiciones o establecer unas penalizaciones si se carece de ellas. En algunos casos concretos se van a establecer códigos.

Cuando comienza su aplicación hay una superposición entre los acuerdos comerciales y los códigos industriales contenidos en la NIRA. Así, por la Orden Ejecutiva n. ${ }^{\circ} 6182$, del 26 de junio de $1933{ }^{93}$, el Presidente delega en el Secretario de Agricultura todos los poderes que le concede la NIRA, excepto los laborales, de las industrias relacionadas con la leche y sus derivados, el tabaco y sus derivados y todos los alimentos. Esta delegación de poderes se amplía por otra Orden Ejecutiva del 20 de octubre de 1933 a las industrias de otros productos agrarios. Sin embargo, el 8 de enero de 1934, las citadas industrias son transferidas de nuevo a la NIRA, y quedan bajo la supervisión de la NRA, organismo encargado de desarrollar la ley industrial, reservándose el Departamento de Agricultura algunas funciones relativas a: precios, comisiones, algún tipo de acuerdos, control de las cuotas de mercado y la siembra. Este trasvase de poderes es reflejado en de forma gráfica en la prensa norteamericana ${ }^{94}$.

Los primeros acuerdos comerciales firmados se aplican a la leche en varias áreas metropolitanas. Igualmente, a través de estos acuerdos se extiende el control de la producción a varios productos agrarios ${ }^{95}$. Todos los acuerdos aprobados bajo la Agricultural Adjustment Act comprenden una o varias de estas cuatro finalidades: control de producción, elevar los precios en origen, organizar la comercialización y venta de los excedentes ${ }^{96}$.

Los resultados de la aplicación de los acuerdos comerciales en la agricultura norteamericana son muy heterogéneos, dependiendo del producto

93 Executive Order n. ${ }^{\circ}$ 6182. Delegation of Certain Functions and Powers Under the National Industrial Recovery Act to the Secretary of Agriculture. Official File, Department of Agriculture, Folder $1 \mathrm{~K}$, Archives, Franklin D. Roosevelt Library, Hyde Park, New York.

94 SHOEMAKER, «The Latest Experiment», Chicago Daily News, Chicago, 1934.

95 Los acuerdos comerciales se aplican al trigo, arroz, tabaco, leche, melocotón, manzana, árboles frutales de hoja caduca, limonero, uva, ciruela, pasa, dátil, fresa, sandia, aceituna, nuez, cacahuete, pacana, espárrago, apio, lechuga, guisante, coliflor, patata, aguarrás y colofonia, bebidas alcohólicas y miel de abejas. En el caso del trigo, arroz, tabaco, cacahuetes y patatas, las medidas de control de producción son usadas para complementar otras iniciativas o como alternativa. Véase Mariam S. FARLEY, 1936, pág. 16.

96 Carta y Memorandum de C. W. Dunning a Glenn McHugh. Codes and/or Marketing Agreements Which Have Been Approved and Signed to November 17, 1933. Official File, Department of Agriculture, Folder 1K, Archives, Franklin D. Roosevelt Library, Hyde Park, New York. 
de que se trate. Edwin G. Nourse, autor de un importante estudio sobre los acuerdos comerciales nos refleja esta situación cuando escribe: «... los resultados que se pueden alcanzar a través de una comercialización controlada, bajo el poder centralizado del gobierno, están muy condicionados por las limitaciones económicas» ${ }^{97}$.

\section{CONCLUSIONES}

La Agricultural Adjustment Act, principal ley agraria del New Deal, pretende introducir unos efectos positivos en la agricultura, reduciendo el volumen de su producción y los excedentes existentes; e incrementando el precio de los productos agrarios, elevando así el poder adquisitivo de los agricultores. La ley agraria favorece el desplazamiento de los ingresos urbanos hacia el mundo rural, al incrementar los precios de los productos del campo. Se busca, que al final, los consumidores de las ciudades se beneficien del mayor poder de compra que alcanzan los agricultores, ya que gracias a él pueden adquirir más productos manufacturados de la industria y demandar más servicios.

Una de las líneas básicas de la reforma agraria del New Deal es la limitación de la extensión de las tierras dedicadas a un determinado cultivo. Para conseguir la adhesión de los agricultores se les subvenciona la reducción de sus producciones, y así poder disminuir sus excedentes. Sin embargo, los granjeros utilizan ese dinero para mejorar la productividad de las tierras que sí cultivan. De este modo, se incrementa la producción aun con menos tierras. Otro de los usos que acostumbra a hacer el agricultor es «entregar» tierras peores, o menos productivas, y seguir cultivando las mejores.

En general, los planteamientos iniciales de la Agricultural Adjustment Act registran una acogida favorable en el agro americano. Al mismo tiempo, se produce una colaboración inesperada por parte de los fenómenos naturales, tales como sequías, tormentas de polvo, inundaciones y huracanes, que se registran en estos años, y que al destruir parte de las cosechas ayudan a reducir la producción de los productos agrarios, uno de los objetivos prioritarios marcados por el gobierno.

Dentro del programa de control de la producción, la $A A A$ otorga sus subvenciones a los propietarios de las fincas. Hay que mencionar, que en

97 Edwin G. Nourse, Marketing Agreements Under the AAA. Washington, D. C.: The Brookings Institution, 1935, págs. 368 y 372 . 
Estados Unidos existe un elevado número de granjeros que son los propietarios de sus explotaciones agrícolas y ganaderas y que van a desempeñar un papel fundamental en la política norteamericana de los años treinta, por ser un grupo aliado de Roosevelt, que ya le apoya en 1933, y que en 1936 va a determinar su reelección. Este colectivo es el que respalda la ley agraria de Roosevelt en un principio, aunque posteriormente se opone a algunas de sus iniciativas por considerarlas demasiado conservadoras.

Sin embargo, a pesar de que en Norteamérica se ha favorecido la concesión de hipotecas sobre sus explotaciones por parte de las entidades bancarias para que los agricultores accedan a la propiedad de la tierra. En Estados Unidos, también hay agricultores que no son los propietarios de las tierras que cultivan. Éstos son los aparceros y los jornaleros, quienes suelen concentrarse en aquellas zonas donde existen áreas de cultivo con explotación intensiva. Este sector de la población rural no se beneficia de las ayudas que establece la Agricultural Adjustment Act. Como consecuencia de esta práctica, se ha acusado a esta medida de favorecer abiertamente los intereses de los grandes propietarios de tierras, con el consentimiento del presidente Roosevelt, ayudándose así a perpetuar la estructura social desigual que existía en el agro americano. 